[Agr. Biol. Chem., Vol. 27, No. 9. p. 633 638, 1963]

\title{
Studies on the Microbiological Transformation of Steroids
}

\author{
Part VII. Nuclear Magnetic Resonance (NMR) Spectra of 19-Hydroxy- \\ steroids and their Application to Microbiological \\ 19-Hydroxylation of Steroids \\ By Takeshi Takahashi \\ Research Laboratories, Takeda Chemical Industries, Ltd., Osaka \\ Received May 11, 1963
}

\begin{abstract}
Some features of the NMR spectra of 19-hydroxy- and 19-acetoxy-steroids were presented and by making use of the features an unknown product of a microbiological transformation of $17 \alpha, 20 \alpha, 21$-trihydroxypregn-4-en-3-one was easily characterized as a 19-acetoxysteroid.
\end{abstract}

\section{INTRODUCTION}

Products in microbiological transformations of steroids have usually been characterized by techniques of classical organic chemistry. But recent progress in physical techniques has often provided simpler and straight methods for characterization of the products. This note also presents another example of such cases. In the course of studies on microbiological transformations of steroids, a simple method for detecting 19-hydroxysteroids was required. Several methods are known to be useful for the purpose, namely methods of $\mathrm{NaOH}$-fluorescence ${ }^{1)}$, of chromotropic $\mathrm{acid}^{2)}$, and of UV absorption spectra in alkaline ethanol $^{3)}$. Although all the methods were examined with some authentic 19-hydroxyand 19-acetoxy- $\Delta^{4}-3$-oxosteroids as well as their corresponding 19-methylsteroids, none of them were found to be satisfactory for detecting 19-hydroxy- (or 19-acetoxy-) steroids in pregnan series. Study by Shoolery and Rogers ${ }^{4)}$,

* Part VI: This Journal, 26, 89 (1962).

1) I.E. Bush, Biochem. J., 50, 370 (1952); R. Neher, Chromatographic Rev., 1, 99 (1959).

2) D.H.R. Barton and P. de Mayo, J. Chem. Soc., 1954, 887 ; A.S. Meyer, Experientia, 111,99 (1955).

3) A.S. Meyer, J. Org. Chem., 20, 1240 (1955) however, suggested a possibility that one can employ NMR spectra for detecting these compounds. This note describes the features of the NMR spectra of a few number of the 19-hydroxy- and 19-acetoxy-steroids and their application to the detection of a new 19hydroxysteroid obtained by a microbiological transformation of $17 a, 20 a, 21$-trihydroxypregn4-en-3-one.

\section{EXPERIMENTAL}

Compounds studied are as follows: 19-hydroxycortexolone (I) ${ }^{5}$, 19,21-diacetoxypregn-4-en-17 $a$-ol-3,20dione (II) $)^{5}$, cortexolone (III), cortexolone 21-acetate (IV) , 19-hydroxyandrost-4-ene-3,17-dione (V) $)^{5)}$, 19acetoxyandrost-4-ene-3,17-dione (VI $)^{6)}$, androst-4-ene3,17-dione (VII), and three kinds of acetates (VIII, IX and $\mathrm{X}$ ) of the conversion products obtained by a fermentation of $17 a, 20 a, 21$-trihydroxypregn-4-en-3one and hydrocortisone with Pellicularia filamentosa f.s. microsclerotia ${ }^{7)}$. In addition, NMR spectra of a number of compounds shown below were compared with those of 19-hydroxy- and 19-acetoxy-steroids: namely 21-acetoxypregna-1,4-dien-17a-ol-3,20-dione, hydrocortisone 21-acetate, cortexolone 21-benzoate, $6 \beta$ -

4) J.N. Shoolery and M.T. Rogers, J. Am. Chem. Soc., 80, 5121 (1958).

5) T. Takahashi and T. Hasegawa, J. Agr. Chem. Soc. Japan, 35, 1399 (1961)

6) The compound was prepared from $\mathrm{V}$ as usual

7) T. Takahashi, This Journal, 27, 639 (1963). 
hydroxycortexolone, $14 a$-hydroxycortexolone, $15 a$-hydroxycortexolone, $9 a$-hydroxyandrost-4-ene-3,17-dione, $6 \beta, 9 \alpha$-dihydroxyandrost-4-ene-3,17-dione, $11 \beta$-hydroxyandrost-4-ene-3,17-dione, androsta-1,4-diene-3,17-dione, $11 \beta$-hydroxyandrosta-1,4-diene-3,17-dione, deoxycorticosterone (XI) and deoxycorticosterone acetate (XII).

The compounds were dissolved in chloroform or pyridine to give 0.2 to $0.4 \mathrm{M}$ solutions and their NMR spectra were obtained at $60 \mathrm{Mcps}$ with a Varian A60 NMR spectrometer. The chemical shifts were expressed, regardless of solvents used, in $\tau^{\prime}$ values, defined as $\left[10-10^{6} \times \Delta / 60 \times 10^{8}\right]$ where $\Delta$ means the line separation (cps) between sample and internal reference, tetramethylsilane.

\section{RESULTS AND DISCUSSION}

(1) Some Features of NMR Spectra of 19-Hydroxyand 19-Acetoxy-steroids.

General features of NMR spectra of steroids have been discussed by Shoolery and Rogers ${ }^{4}$ ) on the basis of examination on 47 steroids but none of them were 19-hydroxy- or 19acetoxy-steroids. In this study NMR spectra of two each of 19-hydroxy- and 19-acetoxysteroids were obtained and compared with those of the corresponding 19-methylsteroids as shown in Table I. The spectra of 19hydroxysteroids displayed no resonance lines of the 19-methyl groups which are always exhibited by those of 19-methylsteroids but, instead, displayed resonance lines of the 19hydroxymethyl groups composed of quartets of the 19-methylene groups and singlets of the 19-hydroxyl groups, the latter being not always able to be assigned. The spectra of 19-acetoxysteroids also displayed no 19-methyl peaks and, instead, exhibited sharp singlets of the 19-acetoxy groups and quartets of the 19-methylene groups.

19-Methylene Groups. The signals of this group are characteristic of the nuclear magnetic resonance of 19-hydroxy- and 19-acetoxysteroids but they are similar to those of the 21-methylene groups in the 21-hydroxy- or 21-acyloxy-20-oxosteroids. The methylene groups encountered in this study may be classified into eight types according to their circumstances as shown in Table II. If the groups were allowed to rotate freely, their signals should be singlets. Occurrence of quartets resulted from AB type couplings between methylene protons may be explained ${ }^{4}$ in terms of hindered rotation and consequent unequal residence times in various rotational conformations of the groups. Table II shows that all the types of the groups gave rise to quartets except those belonging to the 21hydroxymethyl $(17 a-\mathrm{H})$. From the quartets three characteristic constants are generally obtained, namely, $\delta_{A B}$-the difference of chemical shifts between methylene protons, $\mathrm{J}_{\mathrm{AB}}$-the spin-spin coupling constant between

TABLE I. $\tau$ 'VALUES* OF IMPORTANT SIGNALS IN NMR SPECTRA OF 19-HYDROXY- AND 19-ACETOXYSTEROIDS AS WELL AS THE CORRESPONDING 19-METHYLSTEROIDS

\begin{tabular}{|c|c|c|c|c|c|c|c|c|c|}
\hline $\begin{array}{l}\text { Compound } \\
\text { I }\end{array}$ & $\begin{array}{c}\text { Solvent } \\
\text { Py** }\end{array}$ & $\begin{array}{l}18-\mathrm{CH}_{3} \\
9.20(\mathrm{~s})\end{array}$ & $19-\mathrm{CH}_{3}$ & 19-OAc & 21-OAc & $\begin{array}{c}19-\mathrm{OH} \\
?\end{array}$ & $\begin{array}{l}19-\mathrm{CH}_{2} \\
5.85 \text { (q) }\end{array}$ & $\begin{array}{l}21-\mathrm{CH}_{2} \\
4.96 \text { (q) }\end{array}$ & $\begin{array}{c}4-\mathrm{CH} \\
3.88(\mathrm{~s})\end{array}$ \\
\hline III & Py & $9.26(\mathrm{~s})$ & $8.96(\mathrm{~s})$ & & & & & $5.10(\mathrm{q})$ & $4.22(\mathrm{~s})$ \\
\hline II & $\mathrm{Chl}^{\dagger}$ & $9.28(\mathrm{~s})$ & & $7.99(\mathrm{~s})$ & $7.83(\mathrm{~s})$ & & $5.60(q)$ & $5.04(q)$ & $4.09(\mathrm{~s})$ \\
\hline IV & Chl & $9.30(\mathrm{~s})$ & $8.80(\mathrm{~s})$ & & $7.85(\mathrm{~s})$ & & & $5.05(q)$ & $4.30(\mathrm{~s})$ \\
\hline V & Chl & $9.10(\mathrm{~s})$ & & & & $7.08(\mathrm{~s})$ & $6.04(q)$ & & $4.13(\mathrm{~s})$ \\
\hline V & Py & $9.16(\mathrm{~s})$ & & & & 4.55 (b) & 5.89 (q) & & $3.94(\mathrm{~s})$ \\
\hline VI & Chl & $9.08(\mathrm{~s})$ & & $7.99(\mathrm{~s})$ & & & $5.58(\mathrm{q})$ & & $4.08(\mathrm{~s})$ \\
\hline VI & Py & $9.22(\mathrm{~s})$ & & $8.03(\mathrm{~s})$ & & & $5.53(\mathrm{q})$ & & $3.97(\mathrm{~s})$ \\
\hline VII & $\mathrm{Chl}$ & $9.07(\mathrm{~s})$ & $8.77(\mathrm{~s})$ & & & & & & $4.27(\mathrm{~s})$ \\
\hline
\end{tabular}



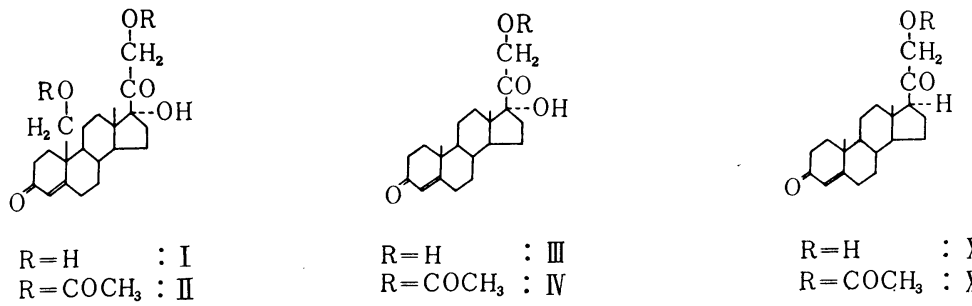

$\mathrm{R}=\mathrm{H}$
$\mathrm{R}=\mathrm{COCH}_{3}: \mathrm{XI}$

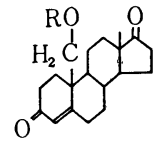

$\mathrm{R}=\mathrm{H} \quad: \mathrm{V}$

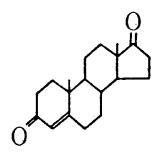

III

CHART 1.

them, and $\tau^{\prime} \mathbf{o}-$ the chemical shift of the midpoint of the quartet. All the constants should be affected more or less by circumstances of the group. From Table $\mathrm{I}$ it is clear that although the chemical shifts $\left(\tau^{\prime} o\right)$ of the methylene protons depended upon the solvent used at measurement, the 21-methylene protons always absorbed at lower field than the 19methylene protons by $0.7 \sim 0.8$ p.p.m. in pyridine and 0.5 p.p.m. in chloroform. A possible explanation is that the 21-methylene protons would be further deshielded by the 20-carbonyl groups. As to $\delta_{A B}$-values, Table II shows that the values of the 19-hydroxymethyls were larger than those of the 21-hydroxymethyls $(17 a-\mathrm{H})$ and that the values of the 19-acetoxymethyls were larger than those of the 21-acetoxymethyls. This fact may be explained from a steric hindrance of rotation of the 19-methylene groups since the groups are axial with respect to rings $A, B$, and $C$ and 1,3-diaxial to $2 \beta$-, $6 \beta$-, $8 \beta$-, and $11 \beta$-protons each. The observation that the 21-hydroxymethyls $(17 a-\mathrm{H})$ gave rise to singlets whereas the 21-acetoxymethyls $(17 a-\mathrm{H})$ afforded quar- tets was already explained ${ }^{4)}$ from the difference between them in sizes of the groups attached to them, the hydroxyl group in the former and the acetoxy group in the latter. If the same explanation could be applied to the $17 a$-hydroxysteroids, the $\delta_{\mathrm{AB}}$-values of the 21-acyloxymethyls (17a-OH) should be larger than those of the 21-hydroxymethyls (17a$\mathrm{OH})$. In fact, the opposite was the case as shown in Table II. In order to elucidate the findings there are at least two factors which must be taken into account, the first being the structural difference and the second being the difference of solvents used at measurement. However, it would be difficult to believe that the presence of $17 a$-hydroxyl groups prevents only the 21-hydroxymethyls from their rotation without hindering the 21-acetoxymethyls. Contribution of the first factor may, therefore, be small. The case is different in the second factor. Since hydroxyl groups are known to interact strongly with pyridine to form a kind of hydrogen bond whereas they interact hardly with chloroform, the 21-hydroxymethyls $(17 a-\mathrm{OH})$ with two hydroxyl 
TABle II. $\delta_{\mathrm{AB}^{-}}$AND $\mathrm{J}_{\mathrm{AB}}$-VAlues of $\boldsymbol{\alpha}$-Methylene Signals of Primary Alcohols

Type of methylene group
21-Hydroxymethyl $(17 \alpha-\mathrm{H})$
21-Acetoxymethyl $(17 \alpha-\mathrm{H})$
21-Hydroxymethyl $(17 \alpha-\mathrm{OH})$
21-Acetoxymethyl $(17 \alpha-\mathrm{OH})$
21-Benzoyloxymethyl $(17 \alpha-\mathrm{OH})$
21-Propionoxymethyl $(17 \alpha-\mathrm{OH})$
19-Hydroxymethyl
19-Acetoxymethyl

\begin{tabular}{|c|c|c|c|}
\hline \multicolumn{2}{|c|}{ Chloroform } & \multicolumn{2}{|c|}{ Pyridine } \\
\hline$\delta_{\mathrm{AB}}(\mathrm{ppm})$ & $\mathrm{J}_{\mathrm{AB}}(\mathrm{cps})$ & $\delta_{\mathrm{AB}}(\mathrm{ppm})$ & $\mathrm{J}_{\mathrm{AB}}(\mathrm{cps})$ \\
\hline 0 & ? & & \\
\hline \multirow[t]{2}{*}{0.19} & 16.7 & & \\
\hline & & $0.39 \sim 0.44$ & $18.6 \sim 19.8$ \\
\hline 0.16 & 17.4 & 0.28 & 17.4 \\
\hline \multirow[t]{2}{*}{0.18} & 18.6 & & \\
\hline & & 0.23 & 19.2 \\
\hline 0.06 & 12.0 & $0.09 \sim 0.14$ & 11.0 \\
\hline $0.48 \sim 0.49$ & 11.4 & $0.44 \sim 0.46$ & 11.4 \\
\hline
\end{tabular}

groups would be strongly solvated only in pyridine solution and consequently be hindered from rotation to a great extent. This assumption was supported by a considerable difference between the $\delta_{\mathrm{AB}}$ of the 21-acetoxymethyls $(17 a-\mathrm{OH})$ in chloroform and that in pyridine. It may be explained from the steric hindrance of solvation that the $\delta_{A B}$ 's of the 19-hydroxymethyls in pyridine were comparable to that in chloroform.

There was observed a remarkable difference between the 19-methylenes and the 21-methylenes in the $\mathrm{J}_{\mathrm{AB}^{\mathrm{B}}}$-values. The $\mathrm{J}_{\mathrm{AB}^{\mathrm{B}}}$-values of methylene protons, $-\mathrm{CH}_{\mathrm{A}} \mathrm{H}_{\mathrm{B}^{-}}$, are usually found to range from 12 to $15 \mathrm{cps}$ and those of the 19-methylenes also lie in this range. But the $\mathrm{J}_{\mathrm{AB}^{\mathrm{B}}}$-values of the 21-methylenes ranging from 16.7 to 19.8 are exceptionally large. According to Gutowsky, Karplus and Grant ${ }^{8)}$, these $\mathrm{J}_{\mathrm{AB}^{-}}$-values may correspond to the $\mathbf{H}_{\mathbf{A}^{-}}$$\mathrm{C}-\mathrm{H}_{\mathrm{B}}$ bond angles of 107 to $106^{\circ}$ which are smaller than the normal tetrahedral angle. No plausible explanation for this fact was found but a comparison of the structural circumstances of the 21-methylenes with those of 19-methylenes suggested that the large $\mathrm{J}_{\mathrm{AB}^{-}}$ values of the 21-methylenes may be ascribable to the 20-carbonyl groups.

19-Hydroxyl Groups. Assignments of the signals of the 19-hydroxyl groups were often difficult because of dependence of their width

\footnotetext{
8) H.S. Gutowsky, M. Karplus and D.M. Grant, J. Chem. Phys., 31, 1278 (1959).
}

and position upon concentration and solvent. For example, NMR spectrum of IV in chloroform displayed a sharp singlet of the 19hydroxyl group at 7.08 whereas in pyridine it exhibited a broad line at 4.55 and in the case of II with two other hydroxyl groups the peak of the 19-hydroxyl group could not be assigned at all.

19-Acetoxy Groups. These groups gave rise to sharp singlets at slightly higher field than the 21-acetoxy groups, 7.99 in chloroform and 8.03 in pyridine. The signals of the 19. acetoxy groups as well as the 19-methylene groups are useful for detecting 19-acetoxysteroids as will be illustrated later.

18-Methyl Groups. The deshielding effects of various functional groups on the chemical shifts of 18-methyl groups have been extensively examined ${ }^{4,9)}$. In connection with this respect the effects of the 19-hydroxyl or 19acetoxy groups on the 18-methyl proton peaks were examined but no significant effects were observed as shown in Table I.

4-Olefinic Protons. In the case of $\Delta^{4}$-3-oxosteroids the peaks of the 4-olefinic protons were readily assigned and the peaks are expected to reflect the structral features of the compounds. From Table I the 19-hydroxyl group in $\mathrm{V}$ is found to decrease the chemical shift of the 4-proton by 0.14 p.p.m. in chloroform and by 0.34 p.p.m. in pyridine. The

9) Y. Kawazoe and others, Chem. Pharm. Bull., 10, 338 (1962). 
same downfield shift was found with the 19acetoxysteroids, namely, the 19-acetoxy groups in II and VI lowered the chemical shifts of the 4-protons by $0.19 \sim 0.21$ p.p.m. in chloroform. In order to compare with the deshielding effect of the 19-hydroxyl group, those of some hydroxyl groups on the 4-olefinic proton peaks were estimated and the results are shown in Table III. From the Table $6 \beta$ and $9 a$-hydroxyls on the ring $\mathbf{B}$ are found to cause a considerable downfield shift whereas $11 \alpha-$ and $11 \beta$-hydroxyls on the ring $\mathrm{C}$, and $14 a$ - and $15 a$-hydroxyls on the ring $\mathrm{D}$ do not cause such a shift. It is noteworthy that among them the 19-hydroxyls caused the largest downfield shift of the 4-olefinic proton peaks. The double bonds at C-1 to C-2 were also found to exert large deshielding effects, the figures being listed in Table III.
TABle III. DOWNFIEld Shifts OF THE 4-OleFINIC PROTON OF $\Delta^{4}-3$-OXOSTEROIDS BY SOME FUNCTIONAL GROUPS

\begin{tabular}{|c|c|c|c|c|}
\hline \multirow{2}{*}{$\begin{array}{l}\text { Functional } \\
\text { group }\end{array}$} & \multicolumn{4}{|c|}{ Downfild shift (p.p.m.) in } \\
\hline & Pyridine & solution & Chloroform & solution \\
\hline $19-\mathrm{OH}$ & 0.34 & (1) & 0.14 & (1) \\
\hline $19-\mathrm{OCOCH}_{3}$ & - & & $0.19 \sim 0.21$ & $(2)$ \\
\hline $6 \beta-\mathrm{OH}$ & 0.19 & (1) & 0.10 & (1) \\
\hline $9 \alpha-\mathrm{OH}$ & 0.14 & (1) & 0.13 & (1) \\
\hline $11 \beta-\mathrm{OH}$ & 0.02 & (1) & -0.03 & (2) \\
\hline $11 \alpha-\mathrm{OH}$ & 0.02 & (1) & -0.01 & (1) \\
\hline $14 x-\mathrm{OH}$ & -0.05 & (1) & - & \\
\hline $15 \alpha-\mathrm{OH}$ & 0.00 & (1) & - & \\
\hline$\Delta^{1}$ & 0.42 & (1) & $0.36 \sim 0.41$ & (3) \\
\hline
\end{tabular}

Minus signs mean the shielding effect and figures in parentheses show the number of the compounds examined.

(2) An Attempted Application of the NMR of the 19Modified Steroids to the Microbiological 19-Hydroxylation of $17 \alpha, 20 \alpha, 21-T r i h y d r o x y p r e g n-4-e n-3-o n e$. For the purpose of detecting 19-modified

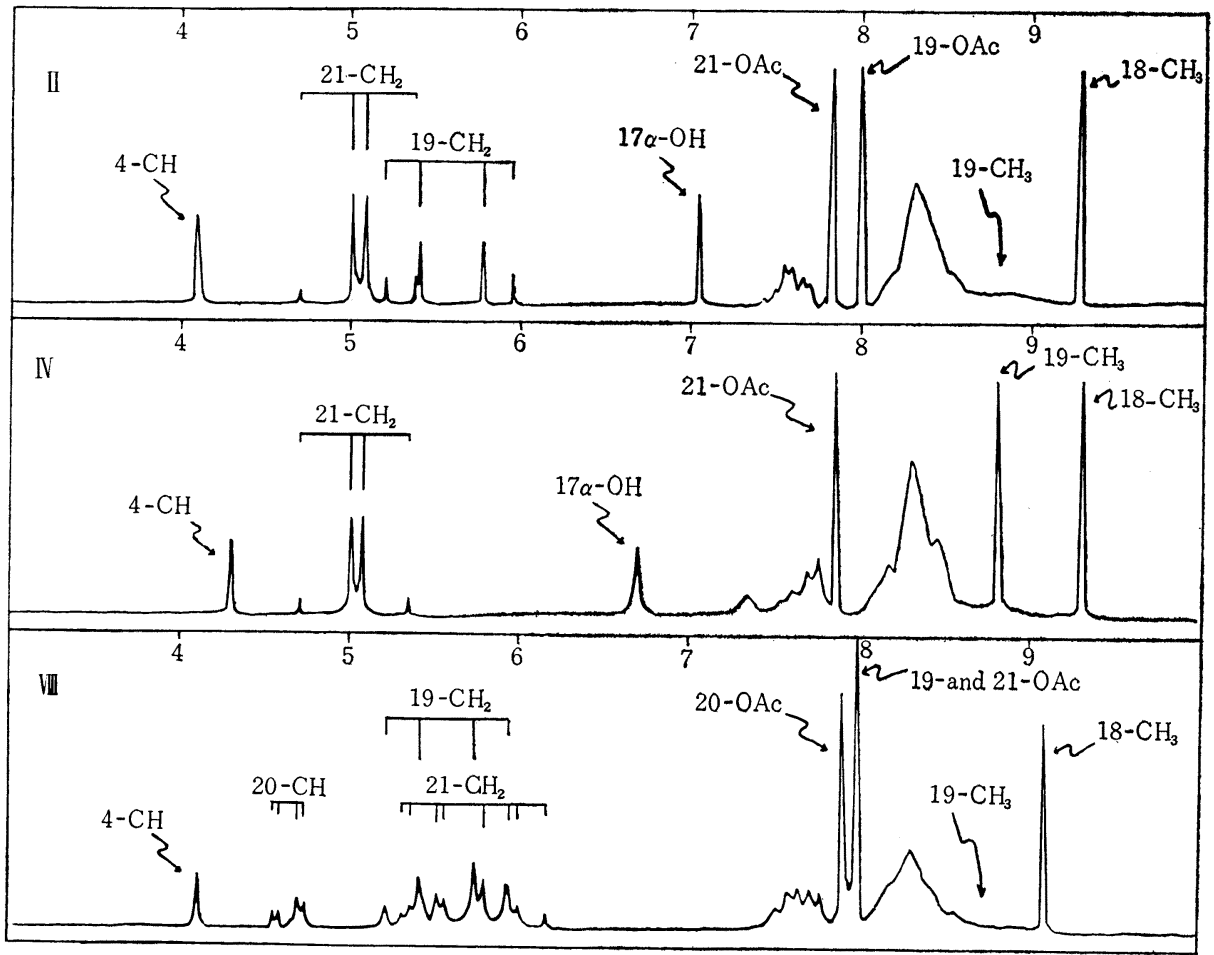

FIG. 1. NMR Spectra of the Chloroform Solutions of II, IV and VIII at $60 \mathrm{Mcps}$. 
steroids it is necessary to make use of the features of their NMR spectra such as 1) absence of 19-methyl proton peaks, 2) presence of the 19-methylene proton peaks, 3) presence of the 19-acetoxy proton peaks (in the case of 19-acetoxysteroids) and 4) occurrence of the downfield shift of the 4-olefinic proton peaks (in the case of $\Delta^{4}$-3-oxosteroids) .

By microbiological transformation of $17 a$, 20a,21-trihydroxypregn-4-en-3-one and hydrocortisone with a strain of Pellicularia filamentosa f.s. microsclerotia which is known to effect 19-hydroxylation of cortexolone, three conversion products were obtained, which were acetylated to give VIII, IX and X. The NMR spectra of both IX and $\mathrm{X}$ exhibited 18- and 19-methyl peaks and hence the two compounds could not be 19-acetoxysteroids. On the other hand the NMR spectrum of VIII did not exhibit the 19-methyl peak as shown in Fig. 2, and instead, it displayed a quartet with $\tau^{\prime}, 5.57, \delta_{\mathrm{AB}}, 0.48$ p.p.m., and $\mathrm{J}_{\mathrm{AB}}, 11.4$ cps and a sharp singlet at 7.98, which over- lapped with the 21-acetoxy proton peak. This fact establishes VIII to be a 19-acetoxysteroid $^{7}$.

It is noteworthy that the nuclear magnetic resonance techniques should be useful not only for detecting 19-hydroxy-, 19-acetoxy- and other 19-modified steroids but also for determination of 18-modified steroids. A disadvantage of the techniques is to require, at least, $10 \mathrm{mg}$ of samples for the measurement of a spectrum.

Outline of this report was presented at the Annual Meeting of the Agricultural Chemical Society of Japan, Fukuoka, April 1, 1961.

Acknowledgement. The author wishes to thank Dr. S. Tatsuoka for his permission to publish this paper and Drs. M. Abe, R. Takeda of the Laboratories and Dr. T. Hasegawa of Institute for Fermentation, Osaka, for their guidance and encouragement throughout this work. He is also indebted to Dr. Y. Asahi for the determination of the NMR spectra. 